\title{
Multi-Expert Multi-criteria Decision-making Model to Support the Conservation of Paramount Elements in Industrial Facilities
}

Daniel Jato-Espino ( $\nabla$ djato@universidadviu.com )

Universidad Internacional de Valencia https://orcid.org/0000-0002-1964-6667

Ángel Martín-Rodríguez

Universidad de Oviedo

Aurora Martínez-Corral

Universitat Politècnica de València: Universitat Politecnica de Valencia

Luis A. Sañudo-Fontaneda

Universidad de Oviedo

\section{Research Article}

Keywords: Conservation, Expert elicitation, Industrial heritage, Multi-Criteria Decision Analysis, Power plant, Technical processes

Posted Date: January 24th, 2022

DOI: https://doi.org/10.21203/rs.3.rs-1271728/v1

License: (9) (1) This work is licensed under a Creative Commons Attribution 4.0 International License. Read Full License 


\section{Multi-expert multi-criteria decision-making model to support}

2 the conservation of paramount elements in industrial facilities

3 Daniel Jato-Espino ${ }^{1, *}$, Ángel Martín-Rodríguez ${ }^{2}$, Aurora Martínez-Corral ${ }^{3}$ and Luis A. Sañudo-Fon4 taneda $^{2}$

$5{ }^{1}$ GREENIUS Research Group, Universidad Internacional de Valencia - VIU, Calle Pintor Sorolla 21, 46002 Valencia, 6 Spain

$7 \quad{ }^{2}$ Department of Construction and Manufacturing Engineering, Institute of Natural Resources and Territorial Planning,

8 University of Oviedo, Calle Gonzalo Gutiérrez Quirós s/n, 33600 Mieres (Asturias), Spain

$9{ }^{3}$ Department of architectural constructions. Universitat Politècnica de València, Camí de Vera s/n, 46022 Valencia, 10 Spain

$11{ }^{*}$ Correspondence: djato@universidadviu.com 
Abstract Modern industrial electricity production is embedded in a global paradigm shift associated with the end of fossil fuels due to climate change, which has led to increased interest in leaving testament of power plants. Multi-Criteria Decision Analysis (MCDA) can help analyse complex interactions between industrial elements, society, culture and nature, providing key benefits when approaching heritage investigations. In this context, this research concerned the design of a Multi-Expert (ME) MCDA methodology to support the selection of paramount heritage elements in power plants based on the collection, processing and harmonisation of the views of a group of international experts in the field. This approach was tested using a case study in the As Pontes power plant (NW Spain), which will be dismantled in a near future. The results achieved pointed out to cooling towers, boilers, chimney and turbine hall as the fundamental elements to preserve due to their relevance across a set of technical, historical and sociocultural criteria. These outcomes proved the usefulness of the proposed approach in favouring the valorisation of industrial facilities as heritage areas protecting the social and cultural history of a territory.

Keywords Conservation; Expert elicitation; Industrial heritage; Multi-Criteria Decision Analysis; Power plant; Technical processes

\section{Introduction}

Industrial activity has prompted a wide variety of technical elements over time. However, they were not valued as part of the wider cultural heritage of a place until the mid-twentieth century [1]. The International Committee for the Conservation of the Industrial Heritage (TICCIH) [2] stressed that these elements were not considered as industrial heritage, a concept that encompasses the professional and cultural ties of industrial activities, whereby each element must have certain value from either a historical, technological, social, architectural or scientific standpoint [3].

This is in line with recent calls for broadening the approach taken to preserve heritage values, which should seek the reuse of elements as assets for economic and social progress [4], as well as for sustainable development [5]. Industrial activities and their relations to heritage are commonly evidenced through facilities of all kinds, machinery, generation and distribution of energy, fluids and materials, as well as the location where the industry develops its activities, which relates to the sociocultural backbone of that territory.

However, governmental concerns in Spain have arisen as a relatively recent phenomena [6]. Consequently, the Spanish Industrial Heritage Plan [7] sets out the need for protection and conservation of heritage based upon its high potential of deterioration and further loss of key elements during their operational life. According to Lin [8], industrial facilities can be converted into tourism assets with educational and heritage values, among others.

Climate change is one of the most significant challenges faced by present-day societies [9], whereby the use of fossil fuels will cease to be viable in order to generate electricity [10]. Accordingly, there is a need for cleaner strategies and technical processes in the industry around the production of electricity. Hence, it is of great interest to leave evidence of electricity generation for future industrial heritage purposes, so that governments can design policies to appropriately preserve current facilities and machinery used in thermal power plants.

Another significant challenge to consider is to find sustainable new uses for industrial facilities and elements [11]. Multi-Criteria Decision Analysis (MCDA) provides a comprehensive way 
of addressing these complex interactions between industrial elements, society and culture, becoming useful to propose the preservation and recovery of original elements of the former industrial activity. These methods allow the integration of a wide range of options, elements and economic, social, historical and environmental concerns, whilst considering the opinion of specialists in the process [12].

Moreover, adaptive reuse strategies for industrial heritage allow the preservation of the symbolic value of a place, while adapting former industrial technical processes towards new uses [13]. In this vein, Langston et al. [14] and Ferretti et al. [15] highlighted adaptive reuse approaches for buildings as key processes to transition towards new uses, incorporating sustainable dimensions related to the environment, society and economy.

Consequently, MCDA tools are fundamental in developing a methodological framework in the lights of varying scenarios, ranging from their historical land use associated to their industrial activity up to their future potential use [16]. Previous studies [16-18] showed that the Analytic Hierarchy Process (AHP) is one of the preferred MCDA tools when conducting research related to the preservation and adaptive reuse of industrial heritage.

MCDA methods have been utilised in recent times in research involving UNESCO's World Heritage places such as the Etna Park, Italy, where sustainable uses and environmental conservation required a robust assessment, proving to be a useful guidance to policy makers according to Sturiale et al. [19]. Ferretti \& Comino [20] also revealed the importance of developing an integrative framework based on MCDA to deal with cultural and natural heritage systems to be recovered for touristic purposes.

These previous investigations focused on industrial and/or cultural heritage assets with a former activity, which is the common place for this sort of research. However, more research is needed to address scenarios with current industrial activity in place prior to the end of its operational life. In addition, there is a lack of studies associated with power plants as potential heritage places, as well as the use of MCDA techniques to help identify the key elements to preserve for future uses. Another gap in the literature lies in the use of MCDA to consider the production process in the plant over the years as a potential core element in terms of industrial heritage.

This paper aims to provide information around these gaps by designing a framework intended to support the conservation of industrial facilities into heritage assets through the preservation of their key elements. To this end, a MCDA methodology based on the collection, processing and harmonisation of the perspectives of a group of experts in industrial heritage was designed and applied to the As Pontes case study, a thermal power plant in Galicia (NW Spain) that is in use nowadays but will be dismantled in the near future.

\section{Methodology}

The approach taken to conduct this study is depicted in Figure 1. First, an overview of the As Pontes power plant is provided, working as a prelude to the definition of the criteria and elements selected for its preservation. Then, a Multi-Expert Multi-Criteria Decision Analysis (ME-MCDA) methodology was built to collect and process the judgments of a panel of experts in industrial heritage, thus enabling the identification of those elements whose conservation is suggested. 


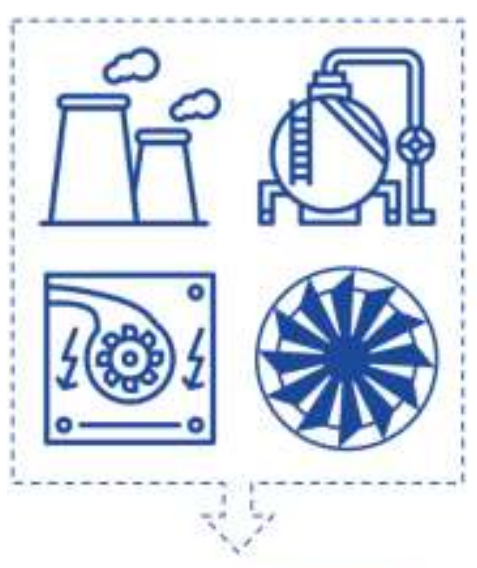

Definition of conservation criteria and description of elements to be preserved

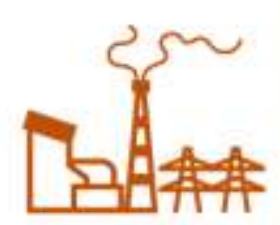

As Pontes power plant 1

Figure 1. Flowchart of the approach taken for the conservation of the As Pontes power plant

\subsection{Case study}

The As Pontes power plant is in As Pontes de García Rodríguez, Galicia, NW Spain. Figure 2 depicts its geographic situation and layout. Its aim was to generate electric power using fossil fuels, while establishing a thermodynamic water-steam cycle. It was originally built to make rational use of the lignite extracted from the open pit mine located in its vicinity.

(1) Design of questionnaires, (2) expert elicitation, (3) weighting of criteria and (4) rating of elements

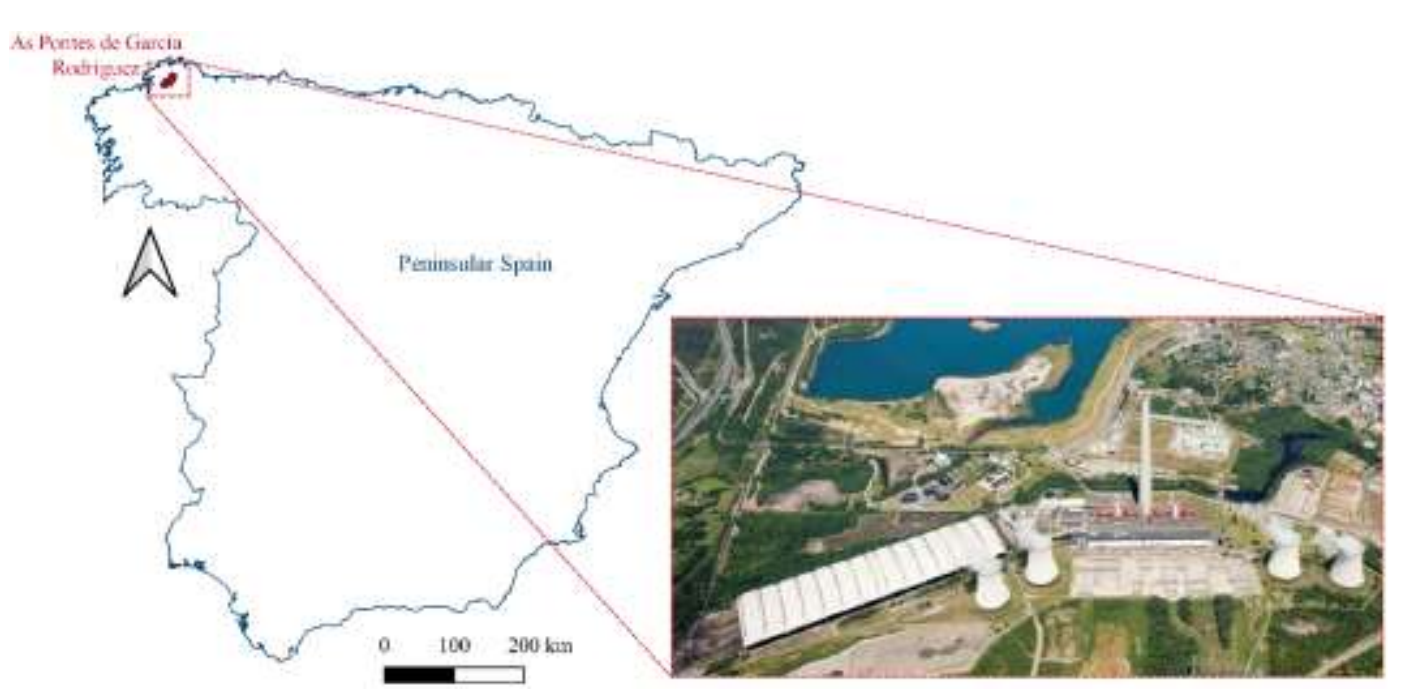

Figure 2. Geographic situation and layout of the As Pontes power plant

The plant began its activity in 1976 with the start-up of the first electric power generation group. Subsequently, three others were added until reaching a total of four groups in 1978 [21]. The highest rates of exploitation were achieved during the 90s, resulting in great economic impacts, including the generation of 3,000 jobs related to this facility [22]. The emission regulations set in Spain during the next two decades led the plant to use imported low-sulphur coal, causing the termination of all lignite mining activities in 2007.

Endesa, the multinational company the power plant belongs to, presented in 2019 a formal request to the Spanish Ministry of Ecological Transition to close the plant, alleging its lack of competitiveness due to the increased price of $\mathrm{CO}_{2}$ emissions. Finally, Endesa updated its strategic 
113 plan at the end of 2019 to remark that its coal-fired power plants are projected to disappear as of 1142022 [23], which becomes the deadline for the As Pontes power plant.

\subsection{Definition of conservation criteria}

116 Seven criteria as listed in Table 1 were defined to support which elements of the As Pontes power 117 plant deserved to be preserved. These criteria were set to account for all the dimensions encom118 passed by industrial heritage, including technical, historical, social, practical and visual consider119 ations. They were defined in accordance with the valuation and selection criteria set in the Spanish 120 Industrial Heritage Plan [7], which includes testimonial $\left(C_{1}\right)$, uniqueness $\left(C_{2}\right)$, architectural $\left(C_{3}\right)$, 121 viability $\left(C_{4}\right.$ and $\left.C_{5}\right)$, social $\left(C_{6}\right)$ and technological $\left(C_{7}\right)$ considerations.

Table 1. Criteria proposed to evaluate the conservation of the As Pontes power plant

\begin{tabular}{ll}
\hline $\boldsymbol{C}_{\boldsymbol{j}}$ & Criterion \\
\hline$C_{1}$ & Importance in the electricity generation process \\
$C_{2}$ & Singularity \\
$C_{3}$ & Aesthetics \\
$C_{4}$ & Ease of preservation \\
$C_{5}$ & Adaptability to new uses \\
$C_{6}$ & Sociocultural interest \\
$C_{7}$ & Work and technology testimony \\
\hline
\end{tabular}

123

Production is essential in the field of industrial heritage due to its relevance to understand how the plant used to work. As such, $C_{1}$ was included in the list of criteria as a representative of the production process, whereby an input (carbon) goes through a boiler where water is transformed into steam, which in turn causes the rotation of a turbine to generate electric power.

Singularity $\left(C_{2}\right)$ stands for those elements whose design involved important technical or scientifical progress. Hence, it may refer to improvements in terms of production, maximum generation or transformation capacity. Also, this criterion can be related to components of large dimensions or other nonconventional characteristics that might justify the interest in safeguarding them.

Aesthetics $\left(C_{3}\right)$ accounts for factors associated with the aspect of the power plant and its integration in the landscape. Therefore, this criterion values the elements in the context of their surroundings or their mimicry in terms of colour or geometry, as well as the interaction of the facility with the environment in terms of land occupation, visual impact, layout distribution, etc.

The maintenance of the power plant with time is addressed by $C_{4}$, whose goal is to prioritise those elements less susceptible to experience degradation. Exposure to weather may result in corrosion or other pathologies depending on the constituent materials. Consequently, preservation must be compatible with new uses, which in turn cannot provoke the deterioration of the elements to be conserved.

New uses must not endanger the patrimonial value of the elements preserved, since this would be against industrial heritage. Thus, adaptability to new uses $\left(C_{5}\right)$ considers positive aspects such as the presence of open spaces or the capacity for coexisting with other activities; instead, complex and large components are difficult to accommodate to different purposes.

The sixth criterion $\left(C_{6}\right)$ values the degree of attraction for the society. It represents the perception of the dwellers in the region in respect of considerations such as the societal modifications 
147 in the urban environment entailed by the power plant, the new activities that might be developed 148 once it is decommissioned, their position with regards to the preservation of the facility, etc.

149 Finally, the last criterion $\left(C_{7}\right)$ appraises the testimony of the activities undertaken in the power 150 plant. On the one hand, it accounts for the evolution of production processes, computing and 151 environmental conservation. On the other hand, this criterion also deals with changes in the daily 152 activities of workpeople, the organization chart of the company, the relationships among the dif153 ferent types of employees, their salary or the existence of subcontractors.

\subsection{Description of the elements to preserve}

155 Due to the complexity of the process for generating electric power, the elements to be rescued in 156 the As Pontes power plant are numerous and diverse. Their breakdown is also complicated due to 157 the existence of interrelationships among them. Based on their characteristics and importance in 158 terms of industrial heritage, a set of 16 elements as shown in Table 2 were shortlisted as potential 159 candidates.

160 They stand for the thermal processing unit of the As power plant, thereby providing a coherent 161 and representative sample of its industrial activity, as stated in the guidelines on industrial heritage 162 currently in force in Spain [7]. Not in vain, these are the elements included in the governmental 163 resolution published by the Spanish Official State Gazette, whereby the As Pontes power plant is 164 projected to be dismantled throughout 2022 [24]. 
Table 2. Potential elements to be preserved in the As Pontes power plant

\begin{tabular}{lll}
\hline $\boldsymbol{E}_{\boldsymbol{i}}$ & Element & Description \\
\hline$E_{1}$ & Coal park & The dimensions of this park, which was devoted to coal storage and homogenization \\
& & $\begin{array}{l}\text { tasks, were } 160 \mathrm{~m} \text { wide by } 592 \mathrm{~m} \text { long. It is formed of a series of prestressed metal } \\
\text { arches with circular section, from which the roof cladding is suspended. }\end{array}$
\end{tabular}

$E_{2}$ External coal The coal used in the plant was transported by road and stored temporarily in an park external park where it was accumulated in piles. Subsequently, the coal went through a tunnel and was poured it onto a conveyor belt by two machines.

$E_{3}$ Coal The coal passed through other conveyor belts in the distribution system, which also distribution resulted in its magnetic separation and crushing. This element had two independent system lines that ensured the continuous fuel supply to the boiler.

$E_{4}$ Air intake The gases derived from combustion went through air preheaters that transmitted their system and thermal energy to the air used for combustion. In turn, these gases were separated precipitators from solid particles to prevent their release to the atmosphere by means of electrostatic precipitators.

$E_{5}$ Boiler The boiler had a natural circulation system and was prepared for the combustion of lignite and subbituminous coal. Its height amounted to 90 meters, with a double line of forced and induced draft fans and 6 columns of burners tangentially arranged

$E_{6}$ Chimney The chimney is a unique structural element whose presence allowed the evacuation of combustion gases. It is $356.5 \mathrm{~m}$ high and contains four metal conduits in a concrete shaft with diameters of $36.5 \mathrm{~m}$ at the base and $18.9 \mathrm{~m}$ at the top

$E_{7} \quad$ Ash and slag Wastes derived from the combustion of coal were collected in the form of slags and extraction fly ash. The extraction system was continuous and discharged into the so-called system ashtray, where slags and fly ash were extracted and subsequently evacuated

$E_{8} \quad$ Ash and slag Slags and fly ash were disposed at a non-hazardous waste landfill specifically landfill designed for their elimination. It was located in a hillside area within the facilities of the thermal power plant. Until 2011, theses wastes were reused by the cement industry.

$E_{9}$ Turbine hall The turbine hall highlights by its delimited occupation and technological complexity, including four turbines and their corresponding alternators. The hall comprises both metal and reinforced concrete frames, which work as a linkage with other areas in the park.

$E_{10}$ Cooling towers The cooling towers enabled the power plant working according to a closed thermodynamic cycle. The cooling process consisted of releasing water in the form of rain and exposing it to the air current that is inside. The flow processed amounts to $38,000 \mathrm{~m}^{3} / \mathrm{h}$, with a thermal leap of $11^{\circ} \mathrm{C}$.

$E_{11}$ Transformer There were 4 transformers corresponding to the output of each of the generation substation groups. These transformers served to change the nominal voltage of the alternators from $18 \mathrm{kV}$ to $410 \mathrm{kV}$, which corresponds to the voltage of the high-power grid.

$E_{12}$ Sewage The entire plant needed potable water for different general uses, such as production, treatment plant human consumption, hygienic services, etc. The system had a clarification capacity of around $200 \mathrm{~m}^{3} / \mathrm{h}$, as well as ozonation, demineralization and filtration systems.

$E_{13}$ River water Water was extracted from the Eume river, which is very close to the power plant. It collection station was collected by means of a pumping machine and then circulated to the water treatment plant.

$E_{14}$ Fuel oil and gas There were 2 fuel oil tanks with a capacity of $4000 \mathrm{~m}^{3}$ and 3 diesel tanks with a oil storage capacity of $100 \mathrm{~m}^{3}$ each. This enabled having sufficient energy available for the tanks complicated start-up processes.

$E_{15}$ Effluent This plant treated effluents between 0.1 and $3.0 \mathrm{~m}^{3} / \mathrm{s}$ meeting the regulations in terms treatment plant of authorization of discharges. The treatment phases included roughing filtration, neutralization, grinding, flocculation, decantation, homogenization and sludge reuse.

$E_{16}$ Environmental The plant had different monitoring stations for environmental control. These included monitoring the analysis of the Eume river water, the evaluation of noise outside the perimeter of infrastructures the facilities and a temporary deposit for hazardous wastes. 
The prioritisation of the elements to be preserved in the As Pontes power plant was undertaken with the support of ME-MCDA. The data used as inputs stemmed from a questionnaire prepared to gather the views of a panel of international experts in industrial heritage. The responses collected were processed using the Analytic Hierarchy Process (AHP) and the Technique for Order of Preference by Similarity to Ideal Solution (TOPSIS), which enabled determining the weights of the criteria and the ranking of elements.

Both methods were selected because of their wide acceptance and use in the field of heritage science [25-28], including applications in which they are coupled with expert elicitation $[29,30]$. In this study, the AHP and TOPSIS methods were also complemented with cluster analysis and a Distance-Based Weighting (DBW) approach, whose combination served to synthetise the results obtained according to the similarity of thought exhibited by the experts.

\subsubsection{Preparation of questionnaires}

A two-phase questionnaire was elaborated using Google Forms to capture the preferences of a panel of experts. Invitations were mostly sent to Spanish respondents, since they should have a better understanding of the specifics of the case study. Still, some international experts were addressed too to capture distant views about the preservation of As Pontes power plant. Most of the specialists consulted were academics, since industrial heritage is a field very prone to technical and/or private work.

After a detailed briefing on the plant and the collection of information about the experience of the respondents, the first phase asked the experts for setting pairwise comparisons about the relative importance of the conservation criteria (Table 1). Seven levels of importance were established, ranging from "much less important" to "much more important".

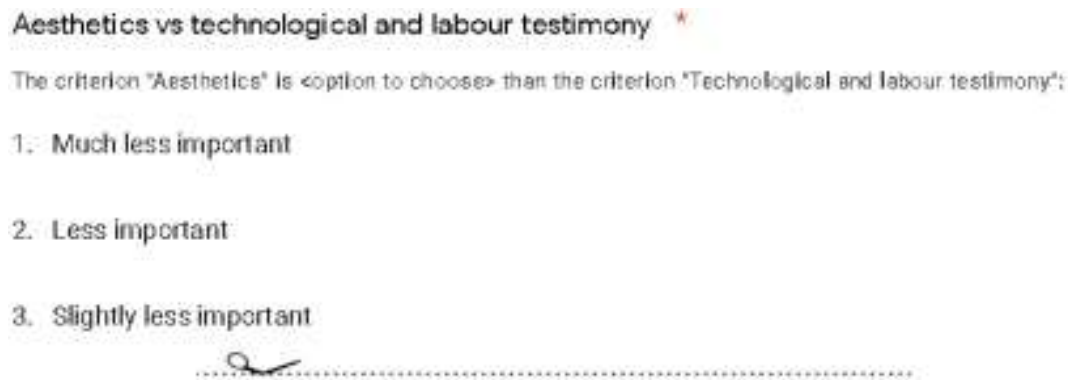

(a)

Assess the 'Importance in the electricity generation process' of the elements to be rescued: *

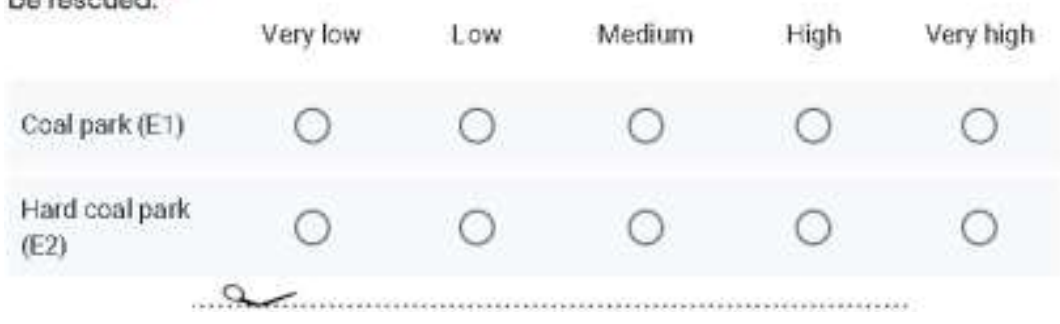

(b)

Figure 3. Excerpts of the questionnaires prepared (a) Conservation criteria (b) Elements to be preserved 
The second questionnaire aimed at evaluating the elements described in Table 2 with respect to the conservation criteria. To this end, a graphical representation of each elements was provided to clarify the characteristics of the As Pontes plant. In this case, the qualitative evaluation was carried out according to a Likert-type scale: very low, low, medium, high, and very high. These judgments were then transformed into semiquantitative values ranging from 1 (very low) to 5 (very high) for subsequent analyses.

\subsubsection{Weighting of conservation criteria}

The criteria in Table 1 were weighted with the support of the AHP method [31], which uses pairwise comparisons to determine the relative importance between two criteria (Table 3). The original scale proposed by Saaty, which consists of nine comparison levels [32], was reduced by removing the most extreme values (1/9 and 9) to facilitate the choice of options by the experts.

Table 3. Reduced comparison scale to set the importance of the conservation criteria

\begin{tabular}{lr}
\hline Relative importance of $\boldsymbol{C}_{\boldsymbol{j}_{\mathbf{1}}}$ with respect to $\boldsymbol{C}_{\boldsymbol{j}_{\mathbf{2}}}$ & Value \\
\hline Much less important & $1 / 7$ \\
Less important & $1 / 5$ \\
Slightly less important & $1 / 3$ \\
Equally important & 1 \\
Slightly more important & 3 \\
More important & 5 \\
Much more important & 7 \\
\hline
\end{tabular}

The linguistic comparisons provided by the experts were arranged in the form of a matrix $[M]$ to enable evaluating their coherence using the Consistency Ratio (C.R.). This term was computed as formulated in Eq. (1), which involves the size $(s)$ and maximum eigenvalue $\left(\lambda_{\max }\right)$ of $[M]$ and the consistency of a series of random matrices (R.I.). Hence, comparisons were considered consistent when C.R. $\leq 0.1$.

$$
C . R .=\frac{\frac{\lambda_{\max }-s}{S-1}}{R . I .}
$$

Those responses resulting in values of $C . R .>0.1$ were processed to become consistent by using the method proposed by Jato-Espino et al. [33]. It consists of modifying the values contained in an inconsistent matrix $[M]$ until Eq. (1) is met, yielding a consistent comparison matrix $[M]^{\prime}$. This is expressed as the minimisation of the Root Mean Square Error (RMSE) of the inconsistent $\left(x_{j_{1} j_{2}}\right)$ and consistent $\left(x_{j_{1} j_{2}}^{\prime}\right)$ comparison values provided by an expert in relation to criteria $j_{1}$ and $j_{2}$ (Eq. (2)). 
217

218

220

221

222

223

224

225

226

227

228

229

230

231

232

Minimize $\sqrt{\frac{1}{n} \sum_{j=1}^{n}\left(\ln x_{j_{1} j_{2}}-\ln x_{j_{1} j_{2}}^{\prime}\right)^{2}}$

subject to: $\quad$ C.R. $\leq 0.1$

$$
\ln x_{j_{1} j_{2}}^{L . B .}<\ln x_{j_{1} j_{2}}^{\prime}<\ln x_{j_{1} j_{2}}^{U . B .}
$$

where $x_{j_{1} j_{2}}^{L . B .}$ and $x_{j_{1} j_{2}}^{U . B .}$ are the lower and upper bounds of $x_{j_{1} j_{2}}$ as indicated in Table 3 (e.g., if $x_{j_{1} j_{2}}=3$, then $x_{j_{1} j_{2}}^{L . B .}=1$ and $x_{j_{1} j_{2}}^{U . B .}=5$ ). Eq. (2) was solved using the Generalized Reduced Gradient (GRG) algorithm [34], leading to a consistent comparison matrix whose values were as close as possible to the original responses given by the experts. In the end, this step was intended to attenuate the difficulties found by the addressees to choose between similar linguistic terms as those included in Table 3.

\subsubsection{Rating of elements to preserve}

The rating of heritage elements across the conservation criteria was carried out using the TOPSIS method [35]. In this context, this method was used to determine how close the elements under consideration were to be ideal in terms of heritage values. To determine this, TOPSIS was applied according to the following steps:

- Obtaining consensual ratings $r_{i j}$ of each element $E_{i}$ across the conservation criteria $C_{j}$ from the opinions provided by the experts.

- Normalising $r_{i j}$ through Eq. (3) to result in $n_{i j}$.

$$
n_{i j}=\frac{r_{i j}}{\sqrt{\sum_{1}^{m} r_{i j}^{2}}}, i=1,2, \ldots, m ; j=1,2, \ldots, n
$$

- Determining the normalised weighted ratings $\left(v_{i j}\right)$ by multiplying the normalised ratings $n_{i j}$ by the weights $w_{C j}$ achieved using the AHP method.

- Calculating the positive $\left(A^{+}\right)$and negative $\left(A^{-}\right)$ideal heritage elements as indicated in Eq. (4).

$$
\begin{aligned}
& A^{+}=\left\{\max _{i} v_{i j}\right\} \equiv\left\{v_{j}^{+} \mid j=1,2, \ldots, n\right\} \\
& A^{-}=\left\{\min _{i} v_{i j}\right\} \equiv\left\{v_{j}^{-} \mid j=1,2, \ldots, n\right\}
\end{aligned}
$$

- Measuring the distances $\left(d_{i}^{+}\right.$and $\left.d_{i}^{-}\right)$from each element under consideration to $A^{+}$and $A^{-}$using Eq. (5). 


$$
\begin{aligned}
& d_{i}^{+}=\sqrt{\sum_{j=1}^{n}\left(v_{i j}-v_{j}^{+}\right)^{2}} \\
& d_{i}^{-}=\sqrt{\sum_{j=1}^{n}\left(v_{i j}-v_{j}^{-}\right)^{2}}
\end{aligned}
$$

- Computing the Relative Closeness $\left(0 \leq R C_{i} \leq 1\right)$ from each element to the ideal element in terms of heritage values through Eq. (6). The higher the value of $R C_{i}$ achieved by an element, the more preferred its conservation was.

$$
R C_{i}=\frac{d_{i}^{-}}{d_{i}^{+}+d_{i}^{-}}
$$

\subsubsection{Cluster analysis}

Cluster analysis was used to partition the opinions provided by the experts according to their similarity. It was applied to the responses collected for the two phases of the questionnaire to demonstrate how sensitive the results achieved were to changes in either the weights of the criteria or the ratings of the elements.

This technique was conceived by Tryon [36] based on the idea that the items included in a group are similar to each other and different from those included in the remaining clusters. Its application started by determining the optimal number of clusters (k) from the responses derived from the two phases of the questionnaire. This was double checked with the support of the Elbow criterion and the Calinski-Harabasz index.

The Elbow criterion is based on calculating the sum of squares of the items within each cluster [37]. This is plotted against the number of clusters, so that the amount of information gained as the latter increases drops at certain point, indicating the optimal number of clusters. The CalinskiHarabasz index is measured as a ratio of between-cluster variance and overall within-cluster variance [38]. Suitable numbers of clusters correspond to high values of this ratio.

Knowing the number of clusters is the first requisite to apply the k-means algorithm, which seeks to minimize the sum of squared Euclidean distances between the items and the centroid of their corresponding cluster [39]. This algorithm consists of the following steps:

- Select $\mathrm{k}$ random items from the dataset to perform as initial centroids.

- Assign the remaining items to its closest centroid according to their Euclidean distance.

- Update the mean value of each cluster every time a new item is added to it.

- Determine whether some items might need being reallocated to a different cluster or not.

- Repeat the last three steps until cluster assignments remain constant.

\subsubsection{Distance-based aggregation}

Although cluster analysis served to partition the opinions received from the experts, there was still a need to aggregate all the responses associated with each group into a single and synthetized 
view. This was achieved using the DBW method [33], which enabled capturing the consensual perspective of each cluster of experts regarding the conservation criteria and elements.

The DBW method is based on giving more importance to those experts whose responses are more alike to the others. This was accomplished by determining the weight $\left(w_{e_{p}}\right)$ of each expert $e_{p}$ according to the Euclidean distance $\left(d_{e_{p_{i}} e_{p_{j}}}\right)$ of his/her responses to those provided by the others. For a number of experts $q, w_{e_{p}}$ can be formulated as shown in Eq. (7).

$$
\left.w_{e_{p}}=\frac{1 / \sum_{p=1}^{q} d_{e_{p_{i}} e_{p_{j}}}}{\sum_{p=1}^{q}\left(1 / \sum_{p=1}^{q} d_{e_{p_{i}} e_{p_{j}}}\right.}\right)
$$

Then, the geometric mean of the opinions of the experts in a cluster $\left(o_{C L_{i}}\right)$ was calculated according to their weighted responses (Eq. (7)) with respect to a certain criterion or element $\left(x_{e_{p}}\right)$, in order to represent the harmonised perspective of such cluster. Hence, Eq. (8) was used to compute the aggregated values obtained for either the conservation criteria or the elements to be preserved.

$$
o_{C L_{i}}=\prod_{p=1}^{q} \ln x_{e_{p}}{ }^{w_{e_{p}}}
$$

\section{Results and discussion}

This section summarizes and discusses the main outputs obtained through the application of the proposed ME-MCDA approach to the analysis of the As Pontes power plant. The results are arranged according to the main parts into which the methodology was divided: processing of questionnaires, weighting of conservation criteria and rating of elements to be preserved.

\subsection{Overview of questionnaires}

The first phase of the questionnaire was responded by 26 experts, which means a response rate of $54.17 \%$ in relation to the original sample of addressees. This figure decreased to 18 in the second phase, a fact that demonstrates the difficulty to maintain cooperation as the number of rounds increases [40]. The correspondence between both phases was not exact, so that some experts only replied to one out of the two questionnaires and some others participated in both.

Overall, the number of respondents involved in the investigation amounted to 33 . This value was in the order of magnitude of the values of sample size suggested in the literature [41]. Figure 4 summarizes the characteristics of the experts who participated at least in one of the phases into which the questionnaire was divided. Given the location of the power plant, most addressees were from Spain (54.55\%). Other regions with more than one participant were United Kingdom (4), Italy (3) and Brazil (2).

The vast majority of respondents belonged to the academia, especially in the role of researchers (almost 70\%). Their experience in industrial heritage ranged from 3 to 40 years, with a mean 
value of 17 years. In line with these values, more than three quarters of the experts considered their expertise in the field to be medium-high or high.

302

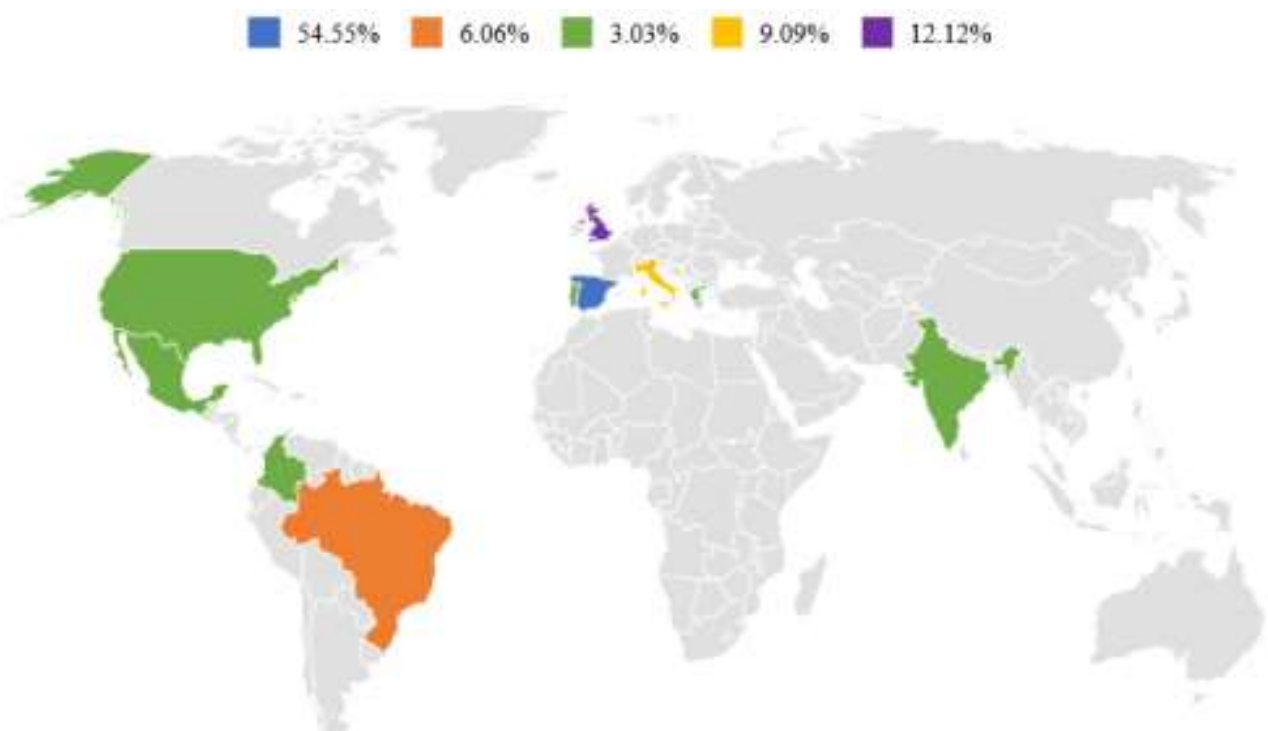

(a)

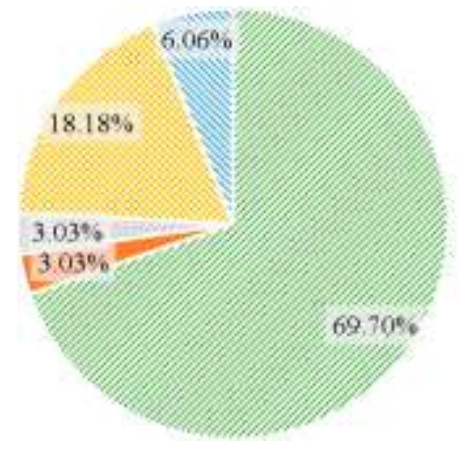

(b)

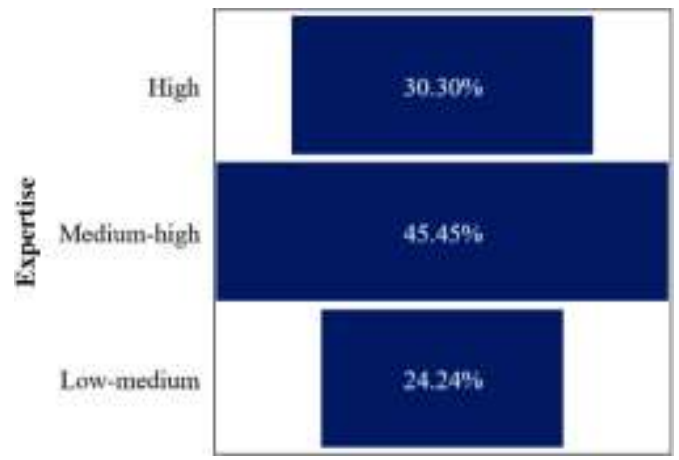

(c)

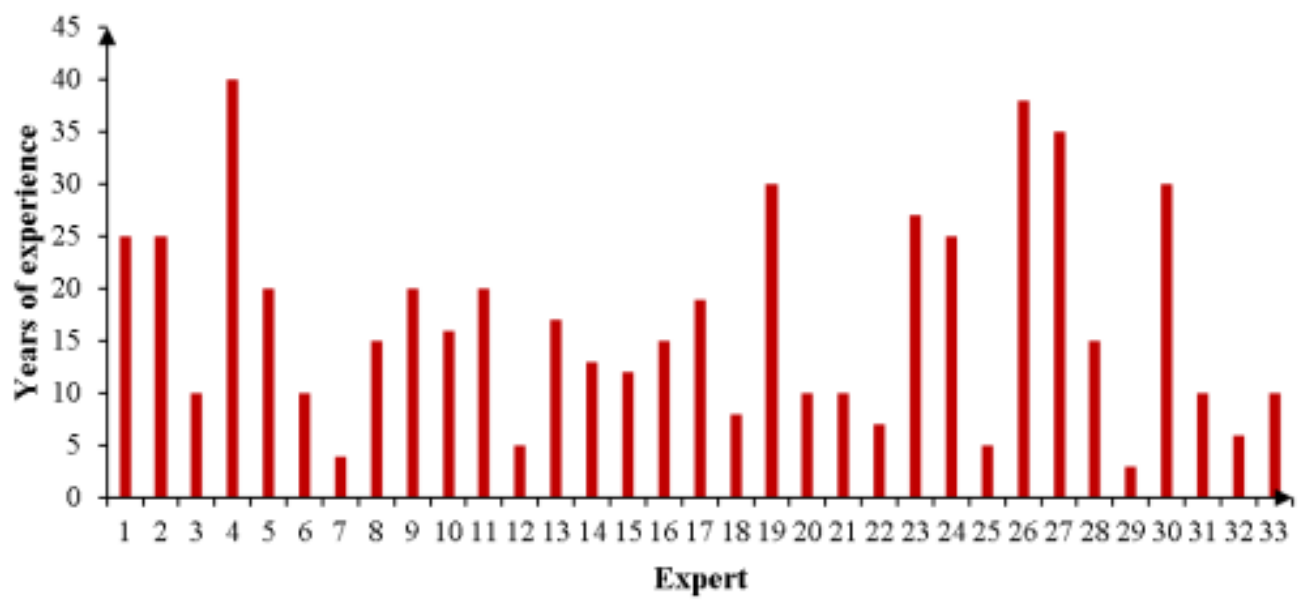

(d)

Figure 4. Summary statistics of the experts addressed (a) Region of origin (b) Profile (c) Degree of expertise (d) Experience (years) 


\subsection{Weighting of conservation criteria}

306

307

308

309

310

311

312

313

314

315

316

317

319

320

321

322

323

324

325

The comparisons provided by the experts to evaluate the criteria were transformed into numerical values according to the AHP scale (Table 3). Then, these values were further processed to obtain a vector of weights for each respondent. The validity of these results was checked using Eq. (1), which revealed that only 5 out of the 27 experts were consistent $(C . R . \leq 0.1)$. This fact supported the simplified scale represented in Table 3 , since the consideration of two additional levels would probably have led to a greater degree of inconsistency [42].

Those comparisons reaching values of $C . R .>0.1$ were processed using the GRG algorithm as formulated in Eq. (2). Thanks to this, all the comparisons were made consistent except for one, whose inconsistency was so high $(C . R=0.58)$ that failed to meet the restrictions of Eq. (2). Table 4 exemplifies the process whereby an inconsistent comparison matrix $(C . R .=0.19)$ became consistent $(C . R .=0.1)$.

Table 4. Inconsistent and consistent comparison matrices and weights obtained before and after applying the Generalized Reduced Gradient (GRG) algorithm

\begin{tabular}{|c|c|c|c|c|c|c|c|c|c|c|c|c|c|c|}
\hline \multirow{2}{*}{$C_{j}$} & \multicolumn{7}{|c|}{ Original inconsistent comparison matrix } & \multicolumn{7}{|c|}{ Consistent comparison matrix (after GRG) } \\
\hline & $C_{1}$ & $C_{2}$ & $C_{3}$ & $C_{4}$ & $C_{5}$ & $C_{6}$ & $C_{7}$ & $C_{1}$ & $C_{2}$ & $C_{3}$ & $C_{4}$ & $C_{5}$ & $C_{6}$ & $C_{7}$ \\
\hline$C_{1}$ & 1 & 1.000 & 5.000 & 5.000 & 0.333 & 1.000 & 0.333 & 1 & 1.053 & 4.422 & 4.634 & 0.361 & 0.928 & 0.374 \\
\hline$C_{2}$ & & 1 & 3.000 & 5.000 & 0.333 & 0.333 & 0.200 & & 1 & 2.765 & 4.354 & 0.344 & 0.353 & 0.233 \\
\hline$C_{3}$ & & & 1 & 5.000 & 0.200 & 0.200 & 0.200 & & & 1 & 3.649 & 0.201 & 0.206 & 0.207 \\
\hline$C_{4}$ & & & & 1 & 0.200 & 0.200 & 1.000 & & & & 1 & 0.189 & 0.194 & 0.643 \\
\hline$C_{5}$ & & & & & 1 & 1.000 & 1.000 & & & & & 1 & 1.025 & 1.030 \\
\hline$C_{6}$ & & & & & & 1 & 1.000 & & & & & & 1 & 1.003 \\
\hline$C_{7}$ & & & & & & & 1 & & & & & & & 1 \\
\hline$W$ & 0.136 & 0.099 & 0.060 & 0.056 & 0.227 & 0.199 & 0.223 & 0.136 & 0.099 & 0.056 & 0.047 & 0.235 & 0.206 & 0.222 \\
\hline
\end{tabular}

An overview of the consistent vectors of weights revealed that the perspectives of the experts differed notably from one another. In response, cluster analysis was applied to group them according to their similarity. The flattening in the curve in Figure 5(a) suggested that the optimal number of clusters might be 3 , whereas the highest value according to the Calinski-Harabasz index confirmed this notion (Figure 5(b)).

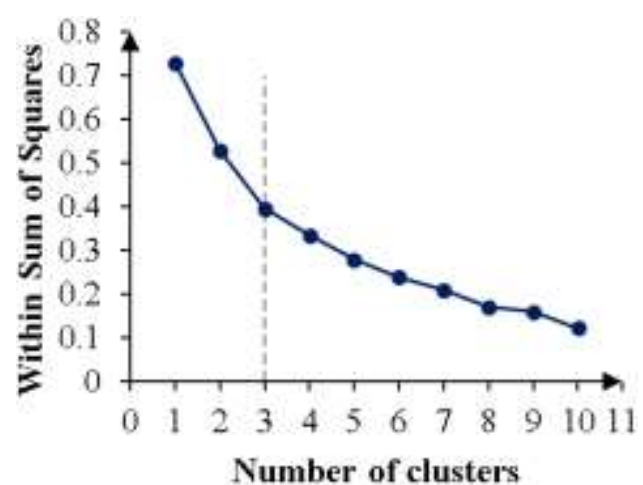

(a)

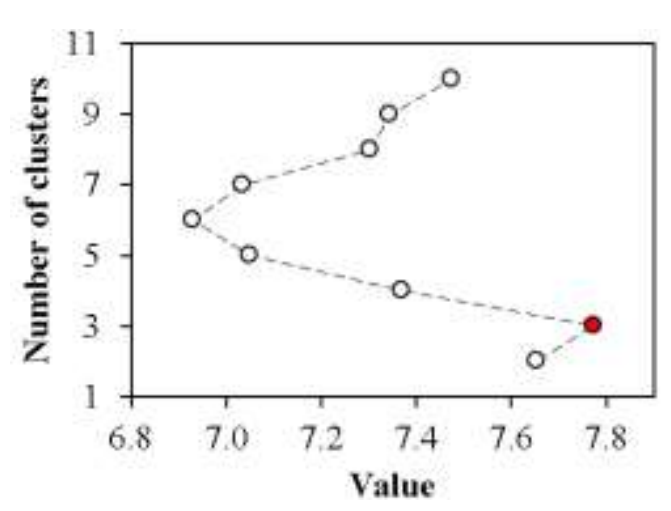

(b)

Figure 5. Optimal number of clusters to group the opinions of the experts regarding the conservation criteria (a) Elbow criterion (b) Calinski-Harabasz index 
The use of the k-means algorithm yielded three groups rather balanced in size, since they were formed by 11, 6 and 8 experts, respectively. The aggregation of weights for these groups using the DBW approach led to the values contained in Table 5. The first cluster (CL) focused on the attractiveness of the elements, emphasizing their reusability $\left(C_{5}\right)$, sociocultural interest $\left(C_{6}\right)$ and preservation of the testimony of the power plant $\left(C_{7}\right)$. This is in line with the main trends found in previous related literature, in which industrial landscapes are deemed to constitute a testimony of the cultural, social and economic conception of a place $[43,44]$.

Other authors coincide with the second cluster of experts in preferring a more pragmatic angle to address industrial heritage, pointing out to the importance of production processes $\left(C_{1}\right)$ in comparison with modern practices [45] and ease of conservation $\left(C_{4}\right)$ [46]. The relevance of the operation in the plant $\left(C_{1}\right)$ was also underlined by the third cluster, whose other main priority laid on the uniqueness of the elements under consideration $\left(C_{2}\right)$. The singularity and representativeness of industrial elements as an indicator of scientific and technological progress has also been considered a priority in some recent investigations in the field $[47,48]$.

Table 5. Weighting clusters obtained after aggregating the comparisons provided by the experts

\begin{tabular}{lccccccc}
\hline \multirow{2}{*}{ Cluster } & \multicolumn{2}{l}{ Criterion } \\
\cline { 2 - 8 } & $\boldsymbol{C}_{\boldsymbol{1}}$ & $\boldsymbol{C}_{\mathbf{2}}$ & $\boldsymbol{C}_{\boldsymbol{3}}$ & $\boldsymbol{C}_{\boldsymbol{4}}$ & $\boldsymbol{C}_{\mathbf{5}}$ & $\boldsymbol{C}_{\mathbf{6}}$ & $\boldsymbol{C}_{\boldsymbol{7}}$ \\
\hline $1(\mathrm{n}=11)$ & 0.105 & 0.146 & 0.057 & 0.085 & 0.171 & 0.204 & 0.177 \\
$2(\mathrm{n}=6)$ & 0.182 & 0.144 & 0.054 & 0.230 & 0.138 & 0.071 & 0.122 \\
$3(\mathrm{n}=8)$ & 0.229 & 0.217 & 0.085 & 0.075 & 0.074 & 0.105 & 0.159 \\
\hline
\end{tabular}

\subsection{Rating of potential elements to preserve}

The responses received to the second questionnaire resulted in 18 matrices including the rating of the 16 elements considered (Table 2) across the 7 criteria (Table 1). Hence, cluster analysis could not be applied straightforwardly in this case. Instead, the mean ratings allocated by the experts to each element were determined as a previous step. Then, the optimal number of clusters was calculated from these mean values. Again, both the Elbow criterion and the Calinski-Harabasz index indicated that this number was 3, as depicted in Figure 6.

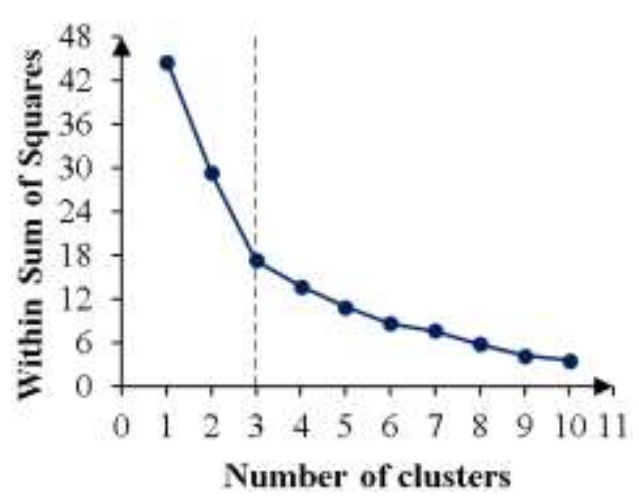

(a)

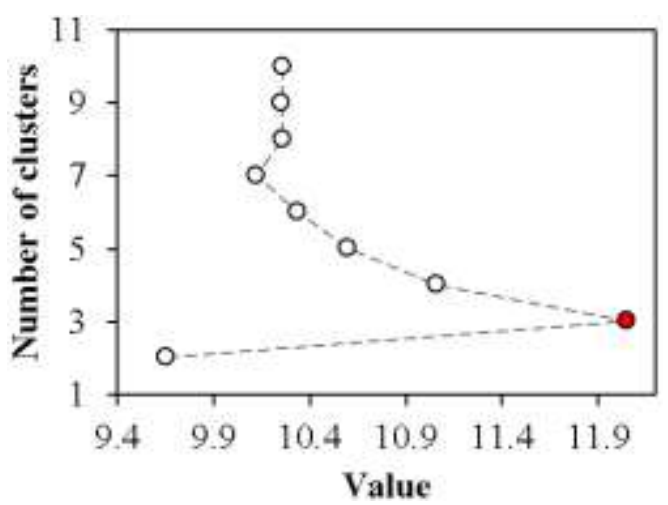

(b)

Figure 6. Optimal number of clusters to group the opinions of the experts regarding the elements to be preserved (a) Elbow criterion (b) Calinski-Harabasz index 
The resulting groups obtained by applying the k-means algorithm were unevenly distributed, to the extent that the third cluster was formed by only one expert. These groups were arranged 355 depending on how the experts rated the contribution of the elements to fulfilling each criterion, 356 from high $\left(\mathrm{CL}_{1}\right)$ to low $\left(\mathrm{CL}_{3}\right)$. Table 6 compiles the weighted values corresponding to each cluster 357 after aggregating the original ratings provided by the experts using the DBW method.

358 Table 6. Weighted ratings per cluster obtained after aggregating the comparisons provided by the experts



360 The joint consideration of weighting and rating clustering yielded 3 groups each, leading to 9 361 scenarios of results $(3 * 3)$ that stemmed from applying the TOPSIS method from the values in 362 Table 6. Then, each normalized weighted matrix was multiplied by the 3 vectors of weights shown 363 in Table 5. Finally, Eqs. (4), (5) and (6) were applied to determine the relative closeness $\left(R C_{i}\right)$ of 364 the elements to an ideal solution. Figure 7 illustrates the results achieved through this process, 365 broken down according to weighting and rating clusters. 
veighting $\mathrm{CL}_{1}$ weighting $\mathrm{CL}_{2}$ 目Weighting CL,

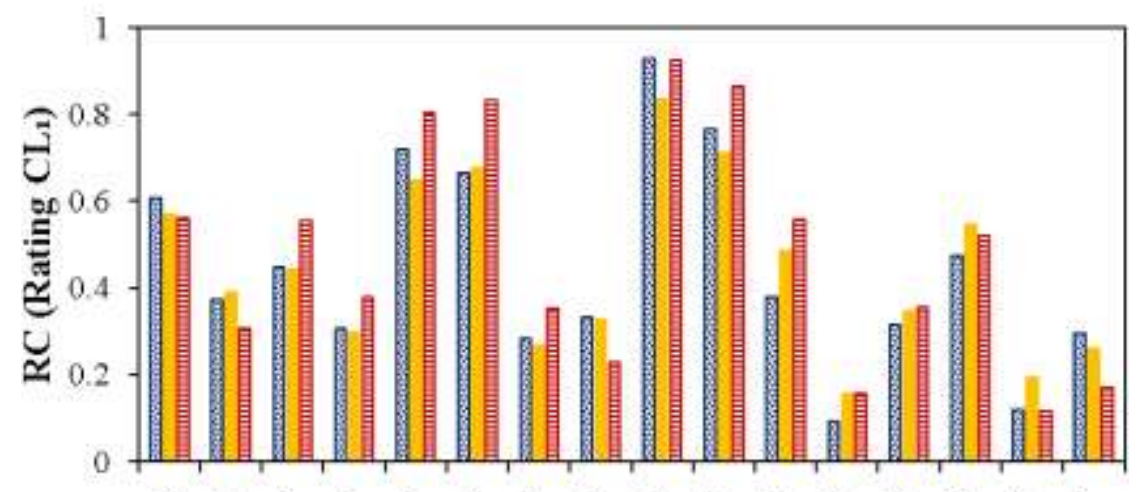

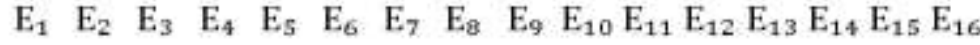

Elements to be preserved

๗Weighting $\mathrm{CL}_{1}$ weighting $\mathrm{CL}_{2}$ 目Weighting $\mathrm{CL}$,

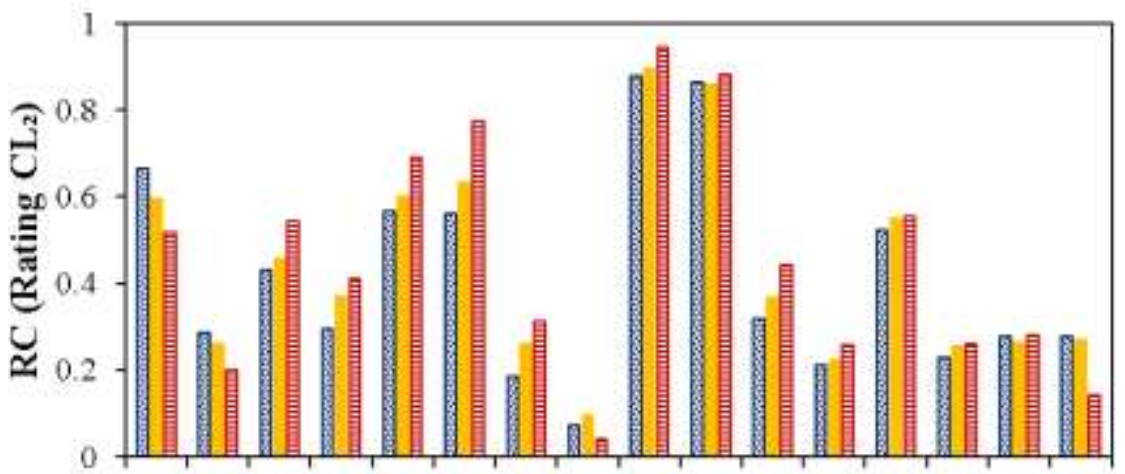

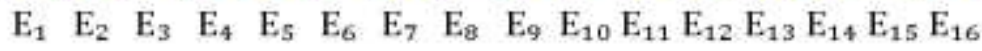

Elements to be preserved

øWeighting $\mathrm{CL}_{1}$ weighting $\mathrm{CL}_{2}$ 目Weighting $\mathrm{CL}$,

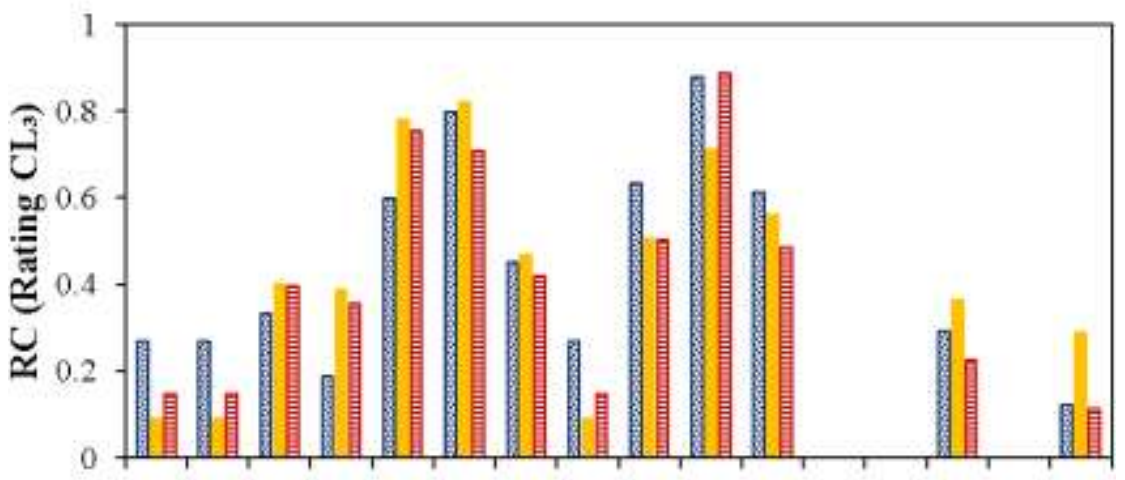

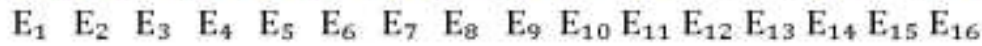

Elements to be preserved

Figure 7. Values of Relative Closeness $\left(\boldsymbol{R} \boldsymbol{C}_{\boldsymbol{i}}\right)$ achieved for each rating and weighting cluster (CL) under consideration

To support the selection of key elements to preserve, the third quartile $\left(\mathrm{Q}_{3}\right)$ of the values of $R C_{i}$ was calculated as shown in Table 7, serving as a threshold to highlight the most preferred $25 \%$ elements under each scenario. As indicated in Table $7, E_{10}$ (cooling towers) was the only element above $\mathrm{Q}_{3}$ in all cases, followed by $E_{5}$ (boiler), $E_{6}$ (chimney) and $E_{9}$ (turbine hall), which were one of the four elements selected in eight out of the nine scenarios under study. These four 
elements formed the shortlisted combination of items to be preserved in six scenarios, which highlighted the solidity and convergence of the results achieved.

According to the US Environmental Protection Agency (EPA) [49], thousands of industrial facilities use large volumes of water to control temperature, for which cooling towers provide a cost-effective and energy efficient solution. As in the case of the As Pontes power plant, the size of these elements can make them impactful in visual terms [50], which further justifies their interest for conservation.

The preponderance of the boiler and turbine hall provide further evidence of the importance of managing the different states of water in thermal power plants, for which safeguarding elements with great value in terms of technological processing and production is crucial [51,52]. Instead, the ranking achieved by the chimney might be rather justified by its impressive magnitude, which in this case amounted to more than $350 \mathrm{~m}$ height. As emphasized by Ali and Al-Kodmany [53], humans have always admired tall structures since ancient times, so that conserving large elements might help attract more visitors [54].

Table 7. Key elements to preserve depending on the combination of rating and weighting clusters

\begin{tabular}{llcr}
\hline Rating $\mathbf{C}$ & Weighting $\mathbf{C} \mathbf{~}$ & Third quartile $\left(\mathbf{Q}_{3}\right)$ & Elements above $\mathbf{Q}_{3}$ \\
\hline 1 & 1 & 0.623 & $E_{5}, E_{6}, E_{9}, E_{10}$ \\
& 2 & 0.589 & $E_{5}, E_{6}, E_{9}, E_{10}$ \\
& 3 & 0.620 & $E_{5}, E_{6}, E_{9}, E_{10}$ \\
& 1 & 0.561 & $E_{1}, E_{5}, E_{9}, E_{10}$ \\
& 1 & 0.596 & $E_{5}, E_{6}, E_{9}, E_{10}$ \\
& 2 & 0.590 & $E_{5}, E_{6}, E_{9}, E_{10}$ \\
3 & 3 & 0.603 & $E_{6}, E_{9}, E_{10}, E_{11}$ \\
& 1 & 0.519 & $E_{5}, E_{6}, E_{10}, E_{11}$ \\
& 2 & 0.489 & $E_{5}, E_{6}, E_{9}, E_{10}$ \\
\hline & 3 & & \\
\hline
\end{tabular}

The As Pontes power plant currently has four cooling towers $\left(E_{10}\right)$, of which only one is proposed to be preserved. The conservation suggestions for this element concern its use as an exhibition space for culture (high ventilation in summer) or plastic arts (painting, sculpture, etc.). The turbine hall $\left(E_{9}\right)$ may perform as a future interpretation centre, including evidence of the control systems, computers and other relevant devices for the production process of the plant.

The chimney $\left(E_{6}\right)$ could be safeguarded as a heritage icon, such that it might be used as an elevator with panoramic view or an environmental station. $E_{5}$ consists of 4 boilers, of which one is proposed to remain in its original condition and the others to be used as a business incubator. This would entail an auxiliary structure to create different floors and opening holes in the walls to be used as windows.

The other elements highlighted in Table 7 were the coal park $\left(E_{1}\right)$ and the substation transformer $\left(E_{11}\right)$. The proposed conservation items for $E_{1}$ are the suspended structure, a stacker-picker machine and part of the conveyor belts, enabling potential uses such as biomass-related industrial activities or open-space for holding events of great magnitude. As for $E_{11}$, substation transformers are elements whose adaption to new uses is complicated. As such, their conservation is proposed as a testimony of their contribution to the generation and transmission of electrical energy. 
Overall, these results, which stem from expert evaluation and research, provide the first step towards the conversion of engineering-related sites into heritage assets. As such, they can be valuable if adopted by governmental bodies at local, regional and national levels to design developmental strategies and policies for regulating industrial heritage.

Otherwise, democratizing the valorisation of industrial facilities would be difficult. The implementation of these practices can entail important benefits across the three pillars of sustainability, since the environmental benefits derived from the closure of industrial facilities might be combined with economic and social developments through local employment creation and increased tourism.

\section{Conclusions}

The outcomes of this study support the preservation of industrial facilities according to their heritage values. The proposed methodology enabled processing the feedback provided by a panel of international experts regarding the criteria and elements involved in the conservation of the As Pontes power plant, whose closure is forecasted to take place in 2022. The variety of responses received led to a series of conservation scenarios that were evaluated separately to ensure the robustness of the results achieved.

All these scenarios coincided in pointing out to four elements that should be preserved to leave testimony of the As Pontes power plant: cooling towers, turbine hall, chimney and boilers. Their predominance laid on their primary role in the production process of coal-fired electricity generation, ease of conservation, sociocultural interest or potential to be adapted for new uses. In this vein, the potential uses proposed for these elements are as follows: business incubator, exhibition area for cultural or plastic arts, interpretation centre or panoramic elevator.

Overall, these outputs can aid decision-making processes related to the conservation of industrial assets at an urban planning level. Increasing regulatory demands in terms of $\mathrm{CO}_{2}$ emissions are leading to the closure of many industrial sites. The adoption of support tools such as the proposed methodology provides an alternative to the dismantling of these facilities. This favours their valorisation in the form of heritage areas intended to leave testimony of the industrial and economic activity of a region, which are in turn linked to its social and cultural history.

Future efforts to continue this line of research should focus on the consideration of additional conservation of criteria and their subsequent refinement according to the appreciations of experts, in order to increase the representativeness of results. Another course of action may focus on testing the methodology developed in this study with other industrial facilities involving different conservation criteria and elements. Finally, the usefulness and applicability of the proposed approach might be enhanced if automated as a web-based tool.

\section{Availability of data and materials}

Not applicable.

442 The authors declare that they have no competing interests 


\section{Funding}

Not applicable.

\section{Authors' contributions}

446 ÁM-R conceived the research; ÁM-R characterised the case study; DJ-E designed and applied the methodology; ÁM-R, DJ-E and LAS-F analysed the results; AM-C, ÁM-R, DJ-E and LAS-F contributed to inviting experts; DJ-E and LAS-F wrote the manuscript; AM-C, ÁM-R, DJ-E and LAS-F revised the manuscript. All authors read and approved the final manuscript.

\section{Acknowledgments}

The authors wish to express their gratitude to the experts that participated in this research, who belong to the following entities: Blog Patrimonio Industrial Arquitectónico, Cátedra Demetrio Ribes, Coventry University, Ferrocarrils de la Generalitat Valenciana, INCUNA, National Technical University of Athens, TICCIH International, TICCIH Spain, Universidad de Sevilla, Universidade de Évora, Universidad Nacional Autónoma de México, Universidad Rey Juan Carlos, Universitat Politècnica de Catalunya and University of Science and Technology Beijing.

\section{References}

1. Wailes R. Industrial Archeology. The industrial monuments survey. The industrial monuments survey. 1967;8:199-203.

2. The International Committee For The Conservation Of The Industrial Heritage. GUIDING PRINCIPLES \& AGREEMENTS [Internet]. TICCIH. 2021 [cited 2021 Apr 11]. Available from: https://ticcih.org/about/about-ticcih/

3. The International Committee For The Conservation Of The Industrial Heritage. THE NIZHNY TAGIL CHARTER FOR THE INDUSTRIAL HERITAGE. Moscow; 2003. p. 4.

4. Saridhe SP, Selvaraj T. Reporting the ancient green construction technology of limecrete slabs adopted in Udaipur, Rajasthan. Journal of Cleaner Production. 2021;279.

5. Gutiérrez-Carrillo ML, Guerrero Delgado MC, Sánchez Ramos J, Arco Díaz J, Bestué Cardiel I, Álvarez Domínguez S. Mitigating damage on heritage structures by continuous conservation using thermal realtime monitoring. Case study of Ziri Wall, city of Granada, Spain. Journal of Cleaner Production. 2021;296.

6. del Pozo PB, Calderón Calderón B, Ruiz-Valdepeñas HP. La gestión territorial del patrimonio industrial en Castilla y León (España): fábricas y paisajes. Investigaciones Geograficas. 2016;2016:136-54.

7. Spanish Ministry of Education, Culture and Sport. Plan Nacional de Patrimonio Industrial [Spanish Industrial Heritage Plan]. Madrid (Spain): Spanish Ministry of Education, Culture and Sport; 2015 p. 46.

8. Lin C-L. The analysis of sustainable development strategies for industrial tourism based on IOA-NRM approach. Journal of Cleaner Production. 2019;241.

9. United Nations Climate Change. What is the Paris Agreement? [Internet]. The Paris Agreement. 2021 [cited 2021 Apr 11]. Available from: https://unfccc.int/process-and-meetings/the-paris-agreement/theparis-agreement

10. Gani A. Fossil fuel energy and environmental performance in an extended STIRPAT model. Journal of Cleaner Production. 2021;297. 
11. ICOMOS Slovenia. Protection and Reuse of Industrial Heritage: Dilemmas, Problems, Examples. Ifko S, Stokin M, editors. Ljubljana; 2017.

12. Śladowski G, Szewczyk B, Barnaś K, Kania O, Barnaś J. The Boyen Fortress: structural analysis of selecting complementary forms of use for a proposed adaptive reuse project. Herit Sci. 2021;9:76.

13. Bottero M, D'Alpaos C, Oppio A. Ranking of adaptive reuse strategies for abandoned industrial heritage in vulnerable contexts: A multiple criteria decision aiding approach. Sustainability (Switzerland). 2019;11:1-18.

14. Langston C, Wong FKW, Hui ECM, Shen LY. Strategic assessment of building adaptive reuse opportunities in Hong Kong. Building and Environment. 2008;43:1709-18.

15. Ferretti V, Bottero M, Mondini G. Decision making and cultural heritage: An application of the MultiAttribute Value Theory for the reuse of historical buildings. Journal of Cultural Heritage. Elsevier Masson SAS; 2014;15:644-55.

16. Bottero M, D'Alpaos C, Marello A. An application of the a'WOT analysis for the management of cultural heritage assets: The case of the historical farmhouses in the aglie castle (Turin). Sustainability (Switzerland). 2020;12.

17. Ribera F, Nesticò A, Cucco P, Maselli G. A multicriteria approach to identify the Highest and Best Use for historical buildings. Journal of Cultural Heritage. Elsevier Masson SAS; 2020;41:166-77.

18. Spina L Della. Adaptive sustainable reuse for cultural heritage: A multiple criteria decision aiding approach supporting urban development processes. Sustainability (Switzerland). 2020;12:1-20.

19. Sturiale L, Scuderi A, Timpanaro G, Matarazzo B. Sustainable use and conservation of the environmental resources of the etna park (unesco heritage): Evaluation model supporting sustainable local development strategies. Sustainability (Switzerland). 2020;12:1-16.

20. Ferretti V, Comino E. An integrated framework to assess complex cultural and natural heritage systems with Multi-Attribute Value Theory. Journal of Cultural Heritage. Elsevier Masson SAS; 2015;16:68897.

21. Endesa. Declaración ambiental 2015 - U.P.T. As Pontes. Madrid (Spain); 2016.

22. Endesa. As Pontes - Fundación Endesa.

23. El País. Endesa formaliza la petición de cierre de las plantas de As Pontes y Carboneras.

24. BOE. Desmantelamiento de los grupos 1, 2, 3 y 4 de la central termoeléctrica de As Pontes en el TM de As Pontes de García Rodríguez (A Coruña) [Dismantling of the groups 1, 2, 3 and 4 of the As Pontes power plant plant in As Pontes de García Rodríguez (A Coruña)]. BOE-A-2021-6771. Sect. 3, 6771 2021 p. 11.

25. Wang Q, Yang C, Tian L, Lu J, Wu F, An J. Safety risk assessment of heritage buildings in metro construction based on SPA theory: a case study in Zhengzhou, China. Herit Sci. 2020;8:100.

26. Wang X, Wang Y, Guo Q, Pei Q, Zhao G. The history of rescuing reinforcement and the preliminary study of preventive protection system for the cliff of Mogao Grottoes in Dunhuang, China. Herit Sci. 2021;9:58.

27. Cui K, Du Y, Zhang Y, Wu G, Yu L. An evaluation system for the development of scaling off at earthen sites in arid areas in NW China. Herit Sci. 2019;7:14.

28. Li J, Chen Y, Yao X, Chen A. Risk Management Priority Assessment of heritage sites in China Based on Entropy Weight and TOPSIS. Journal of Cultural Heritage. 2021;49:10-8.

29. Al-Sakkaf A, Bagchi A, Zayed T, Mahmoud S. Sustainability assessment model for heritage buildings. SASBE [Internet]. 2021 [cited 2022 Jan 13];ahead-of-print. Available from: https://www.emerald.com/insight/content/doi/10.1108/SASBE-03-2021-0049/full/html

30. Mishra PS, Muhuri S. Grading of architectural heritage using AHP and TOPSIS methods: a case of Odishan Temple, India. JCHMSD [Internet]. 2021 [cited 2022 Jan 13]; ahead-of-print. Available from: https://www.emerald.com/insight/content/doi/10.1108/JCHMSD-07-2020-0096/full/html

31. Saaty TL. The Analytic Hierarchy Process: Planning, Priority Setting, Resource Allocation. New York 
32. Saaty TL. How to make a decision: The analytic hierarchy process. European Journal of Operational

33. Jato-Espino D, Indacoechea-Vega I, Gáspár L, Castro-Fresno D. Decision support model for the selection of asphalt wearing courses in highly trafficked roads. Soft Computing. 2018;

34. Abadie J, Carpentier J. Generalization of the Wolfe reduced gradient method to the case of nonlinear constraints. Optimization. 1969. p. 37-47.

35. Hwang CL, Yoon K. Multiple Attribute Decision Making. Methods and Applications: a State-of-theart Survey. Berlin (Germany): Springer-Verlag; 1981.

36. Tryon RC. Cluster Analysis: Correlation Profile and Orthometric (factor) Analysis for the Isolation of Unities in Mind and Personality. Ann Arbor (U.S.): Edwards Brothers Malloy; 1939.

37. Syakur MA, Khotimah BK, Rochman EMS, Satoto BD. Integration K-Means Clustering Method and Elbow Method for Identification of the Best Customer Profile Cluster. IOP Conference Series: Materials Science and Engineering. 2018.

38. Lukasik S, Kowalski PA, Charytanowicz M, Kulczycki P. Clustering using flower pollination algorithm and Calinski-Harabasz index. 2016 IEEE Congress on Evolutionary Computation, CEC 2016. 2016. p. 2724-8.

39. Steinley D. K-means clustering: A half-century synthesis. British Journal of Mathematical and Statistical Psychology. 2006;59:1-34.

40. Beullens K, Loosveldt G, Vandenplas C, Stoop I. Response Rates in the European Social Survey: Increasing, Decreasing, or a Matter of Fieldwork Efforts? Survey Methods: Insights from the Field. 2018;1-12.

41. Keeney S, McKenna H, Hasson F. The Delphi Technique in Nursing and Health Research. Hoboken, New Jersey (U.S.): Wiley-Blackwell; 2010.

42. Sato Y. Comparison between multiple-choice and analytic hierarchy process: Measuring human perception. International Transactions in Operational Research. 2004;11:77-86.

43. Loures L. Industrial Heritage: The past in the future of the city. WSEAS Transactions on Environment and Development. 2008;4:687-96.

44. Xie PF. A life cycle model of industrial heritage development. Annals of Tourism Research. 2015;55:141-54.

45. Szromek AR, Herman K, Naramski M. Sustainable development of industrial heritage tourism - A case study of the Industrial Monuments Route in Poland. Tourism Management. 2021;83:104252.

46. Yung EHK, Lai LWC, Yu PLH. Public decision making for heritage conservation: A Hong Kong empirical study. Habitat International. 2016;53:312-9.

47. Claver J, Sebastián MA, Sanz-Lobera A. Opportunities of the Multicriteria Methods in the Study of Immovable Assets of the Spanish Industrial Heritage. Procedia Engineering. 2015;132:175-82.

48. Pardo Abad CJ. Valuation of Industrial Heritage in Terms of Sustainability: Some Cases of Tourist Reference in Spain. Sustainability. 2020;12:9216.

49. US EPA O. Cooling Water Intakes [Internet]. 2015 [cited 2022 Jan 14]. Available from: https://www.epa.gov/cooling-water-intakes

50. Krätzig W. From large natural draft cooling tower shells to chimneys of solar upwind power plants. Colgone (Germany); 2012.

51. Zhang J, Cenci J, Becue V, Koutra S. The Overview of the Conservation and Renewal of the Industrial Belgian Heritage as a Vector for Cultural Regeneration. Information. 2021;12:27.

52. Panagopoulou A, Vroom J, Hein A, Kilikoglou V. Production Technology of Glazed Pottery in Chalcis, Euboea, during the Middle Byzantine Period. Heritage. 2021;4:4473-94.

53. Ali MM, Al-Kodmany K. Tall Buildings and Urban Habitat of the 21st Century: A Global Perspective. Buildings. 2012;2:384-423. 
54. Bleker J. Redevelopment of large-scale industrial heritage. Delft (The Netherlands): Delft University of Technology, Faculty of Architecture and the Built Environment; 2015 p. 37. Report No.: 4022769. 